\title{
Position accuracy evaluation of the modernized Polish DGPS
}

\author{
Marek Dziewicki, M. Sc. \\ Maritime Office Gdynia \\ Cezary Specht, Assoc. Prof. \\ Polish Naval Academy
}

\begin{abstract}
Polish Maritime DGPS system has been modernized to meet the requirements set out in IMO resolution for a future GNSS, but also to preserve backward signal compatibility of user equipment. Having finalized installation of the new technology L1, L2 reference equipment performance tests were performed. This paper presents results of the long-term signal measuring campaign of the DGPS reference station Rozewie, which was performed in July 2009. Final results allowed to verify repeatable and absolute accuracy of the system after the modernization. Obtained statistics were compared to past measurements performed in 2005 when previous system infrastructure was in operation.
\end{abstract}

Keywords: radionavigation; DGPS position; DGPS transmission; accuracy evaluation; static position measurement; absolute accuracy; sccatter plot; DGPS monitoring; ellipsoid transformation

\section{INTRODUCTION}

Maritime DGPS system was developed to provide position and integrity information to maritime users. This service based on reference stations and MF radio beacons can distribute differential GPS corrections to increase position accuracy, distribute integrity warning to satisfy navigation requirements in coastal navigation and hydrographic survey.

The first Polish DGPS station was established by Polish Hydrographic Office in 1994, finally the system was composed of two independent maritime reference stations located in Rozewie and Dziwnów and common control station in Gdynia. Both RS stations equipped with local integrity monitors were remotely controlled by PSTN network. Due to common research projects performed by Polish Naval Academy and Maritime Office Gdynia, the infrastructure of the system was gradually improved. Tests had mainly been focused on coverage, accuracy and availability of beacons' signals. Then hardware and software of the system have been entirely modernized in 2007, by replacing obsolete L1 code receivers with new type L1, L2 as well as a set of new technology antennas.

\section{DGPS-PL NETWORK}

National radio-navigation policy assessed the current and potential use of the DGPS in navigation, therefore concluded that there was a requirement to improve functionality while modernized. It was evident, that any new approaches that could meet higher requirements and provide enhanced services, had to preserve backward compatibility of existing users' equipment. According to IALA recommendation [IALA 2006], the baseline principles for the re-capitalization of the Polish DGPS system were as follows:

- backward compatibility with legacy signals

- solution supported by international standards

- flexibility for future service requirements

- long life-time.

Polish DGPS system has been modernized during the last two years (2007-8) to meet the requirements set out in IMO Resolution A.915(22) to contribute to the provision of navigational and engineering position-fixing, including navigation in harbour entrances, port approaches and other congested waters. The hardware RSIM solution has been adopted for the re-capitalization on grounds of market availability and lowest cost.

A conception of communication in the system (Fig. 1) is based on operation of reference stations (RS) and far field remote integrity monitors (IM) via IT network, continuously controlled by a Control Station.

There are two reference stations: RS Dziwnów - at west coast, and RS Rozewie at north-east, coast, has been equipped with local integrity monitors (RSIM model). Both sites are being under permanent control of Control Station in Gdynia, where a dedicated server continuously gathers operational information from all RS sites and remote integrity monitors. Thus a living data base of system performance is available there in real time. 


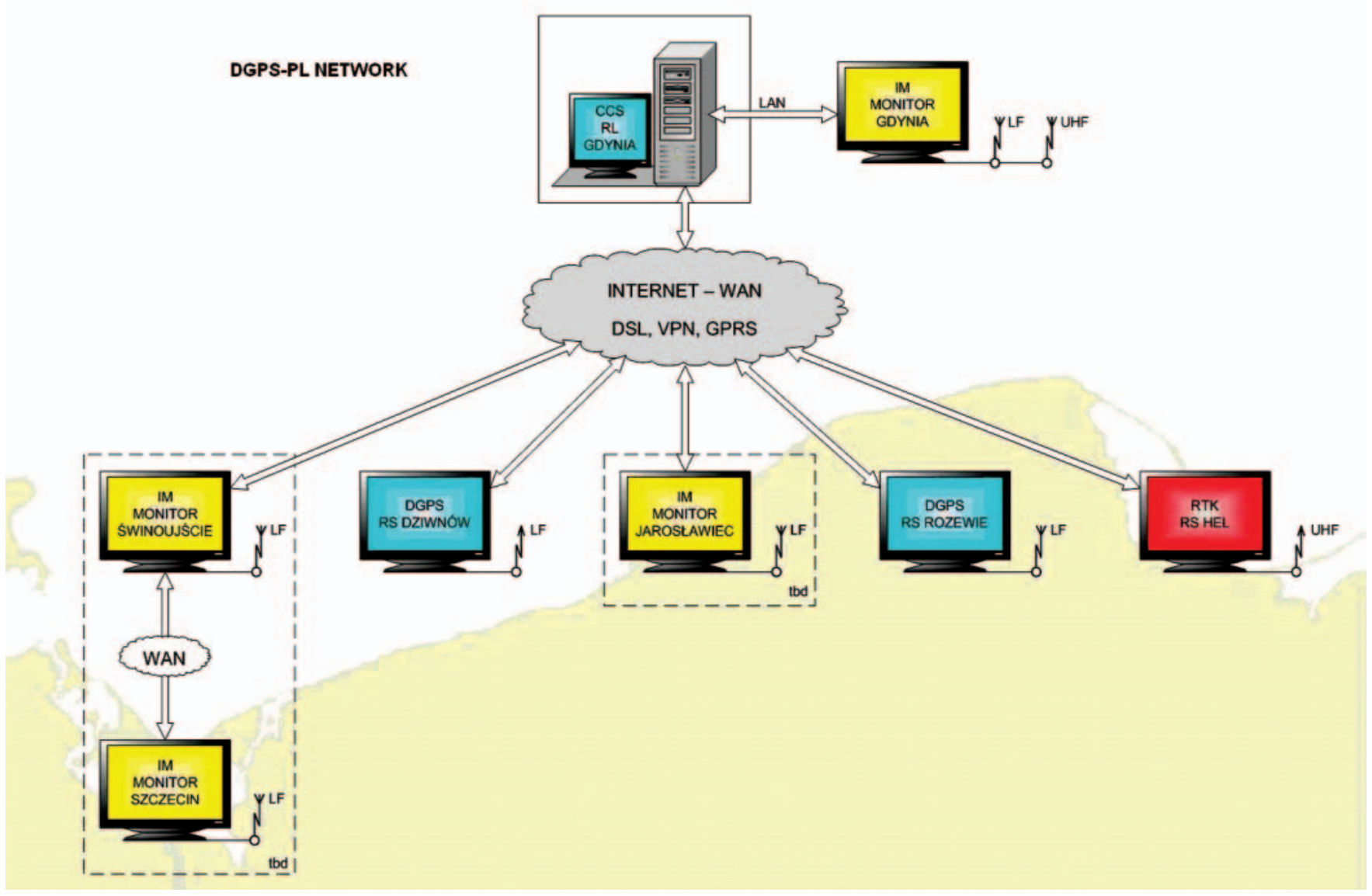

Fig. 1. Block diagram of modernized Polish DGPS and RTK network [1]

\section{SYSTEM COMPONENTS AND PERFORMANCE}

Both reference beacon stations Dziwnów and Rozewie are equipped with local PCs remotely operated and controlled via wide area network from Control Station located in Gdynia. Quality of DGPS broadcast is being checked and evaluated by local integrity monitors (IM) and one remote LF DGPS monitor in Gdynia port. The corrected DGPS position accuracy is limited by the quality of the position information of the reference points. For high precision applications, the reference antenna should have a stable center (electrical center of the antenna) and should not be affected by reflected signals (multipath mitigation) and/or radio interference (jamming resistance). To overcome these problems a choke -ring antennas were installed which performance is particularly effective in reducing the effects of multipath. Daily reports and data on availability of the signal are gathered by local PCs then can be transferred to the data base of Control Station in Gdynia.
To ensure signal availability at required level of $99,5 \%$ for a single site beacon station, a redundancy of major functions is fundamental, so that station will continue uninterrupted work in case of a single hardware failure. Therefore, main blocks of each RS beacon station are doubled. It contains two independent reference L1, L2 receivers, two MSK modulators and dual MF beacon transmitters. Station integrity is under control of single local integrity monitor (L1 DGPS receiver) plus one broadcast station controller - a high end industrial $\mathrm{PC}$ well equipped with multiport cards. Each reference station includes a UPS and a telecommunication equipment: DSL modem, router, network switch. It was recognised that certain reference station and integrity monitor threshold settings are vital to the proper performance of the RS station. A list of parameters and recommended range of settings can be found in IALA recommendation [IALA 2004]. The set of RTCM messages and frequencies being broadcast from Polish DGPS beacon stations is shown in Table 1 . The local integrity monitor tests the quality of the own beacon transmission by

Tab.1. Polish DGPS characteristics

\begin{tabular}{|c|c|c|c|c|c|c|c|c|}
\hline \multicolumn{3}{|c|}{ Table of DGNSS Stations } & \multicolumn{2}{|c|}{ Country: POLAND } & \multicolumn{4}{|c|}{ Date of last amendment: July 2009} \\
\hline \multirow{2}{*}{$\begin{array}{l}\text { Station } \\
\text { name }\end{array}$} & \multicolumn{2}{|c|}{ Identification Nos } & \multirow{2}{*}{$\begin{array}{c}\text { Geographical } \\
\text { Position } \\
\text { Lat/Lon }\end{array}$} & \multirow{2}{*}{$\begin{array}{l}\text { Station in } \\
\text { operation }\end{array}$} & \multirow{2}{*}{$\begin{array}{c}\text { Integrity } \\
\text { Monitoring }\end{array}$} & \multirow{2}{*}{$\begin{array}{l}\text { Transmitted } \\
\text { message } \\
\text { types }\end{array}$} & \multirow{2}{*}{$\begin{array}{c}\text { Freq } \\
(\mathbf{k H z})\end{array}$} & \multirow{2}{*}{$\begin{array}{l}\text { Bit } \\
\text { Rate } \\
\text { (bps) }\end{array}$} \\
\hline & $\begin{array}{l}\text { Reference } \\
\text { Station(s) }\end{array}$ & $\begin{array}{c}\text { Transmitting } \\
\text { Station }\end{array}$ & & & & & & \\
\hline Dziwnów & $\begin{array}{l}741 \\
742\end{array}$ & 481 & $\begin{array}{l}54^{\circ} 01^{\prime} \mathrm{N} \\
14^{\circ} 44^{\prime} \mathrm{E}\end{array}$ & yes & yes & $9,3,7,16$ & 283.5 & 100 \\
\hline Rozewie & $\begin{array}{l}743 \\
744\end{array}$ & 482 & $\begin{array}{l}54^{\circ} 49^{\prime} \mathrm{N} \\
18^{\circ} 20^{\prime} \mathrm{E}\end{array}$ & yes & yes & $9,3,7,16$ & 301.0 & 100 \\
\hline
\end{tabular}


receiving and applying own corrections. The IM software continuously monitors position accuracy, signal availability, every single tracked satellite, GPS geometry, RTCM data correctness and quality, as well as transmitted signal strength (SS, SNR). When any 'alarm condition' is detected, an alarm message is immediately set for local response and switching to optional station (secondary configuration) can happen. In case of integrity alarm - a warning message will automatically be broadcast to all users/ships in the area within time of $10 \mathrm{~s}$.

\section{SYSTEM ACCURACY EVALUATION}

In order to evaluate new characteristics of the modernized DGPS system, a measurement campaign took place over the time span between 30th of June and 26th August 2009. Pseudorange (PRC) corrections type 9-3 broadcasted from DGPS reference station Rozewie were received and recorded by a single frequency (L1) receiver installed in Gdynia, $40 \mathrm{~km}$ from the transmitting MF beacon. These tests were focused on evaluation of horizontal and vertical accuracies of the 3D position. Results were based on long term observations (26 days) registered with 10 s sampling rate. Data files were containing position time series in the format of NMEA 0183 standard, GGA referenced to WGS-84 datum $(a=6378137.00 \mathrm{~m}, \mathrm{~b}=6356752314 \mathrm{~m})$. The reference point for the receiver was set in the Port of Gdynia with coordinates: $5431.75524 \mathrm{~N}, 1833.57418 \mathrm{E}, \mathrm{H}=68.07 \mathrm{~m}$. The previous one (in 2005) was installed almost at the same position. Obtained results (statistics) has been compared to ones performed in 2005 [4].

Let's define an absolute accuracy as a the statistical difference between position measurements and a surveyed benchmark for any point within the service volume over a specified time interval [SPS 2001]. When there is no information about surveyed coordinates the statistics could be related to estimated (average) position (repeatable accuracy).

Measured ellipsoidal coordinates were transformed to Gauss-Kruger $(\mathrm{X}, \mathrm{Y})$ conformal coordinates: based on relations; $[2,3,5]$

$$
\begin{aligned}
& Y=R \cdot\left[d L \cos (B)+\frac{d L^{3}}{6} \cos (B)^{3}\left(1-t^{2}+\eta^{2}\right)+\right. \\
& \left.+\frac{d^{5}}{120} \cos (B)^{5}\left(5-18 t^{2}+t^{4}+14 \eta^{2}-58 \eta^{2} t^{2}\right)\right]
\end{aligned}
$$

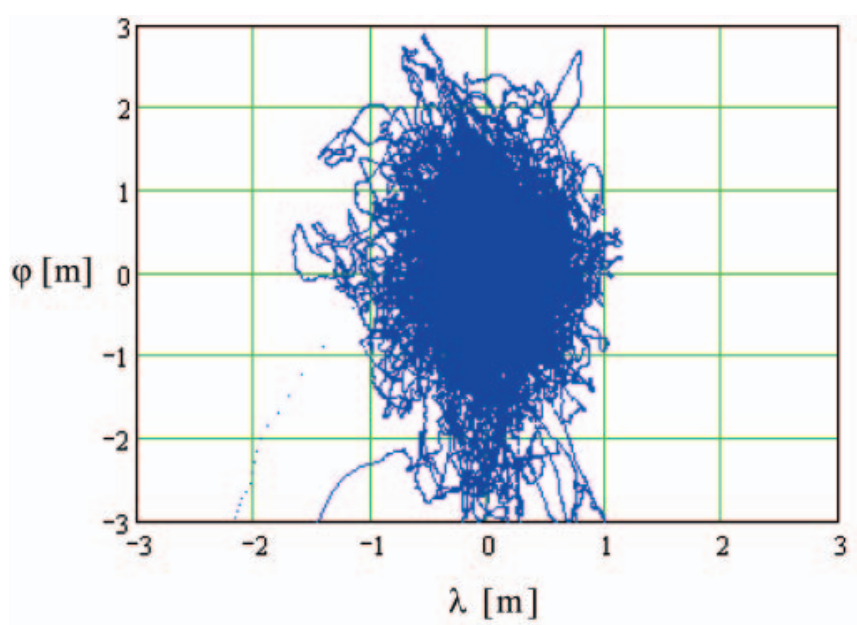

$$
\begin{gathered}
X=k \cdot R\left[\frac{\mathrm{S}(\mathrm{B})}{\mathrm{R}}+\frac{\mathrm{dL}^{2}}{2} \sin (\mathrm{B}) \cos (\mathrm{B})+\frac{\mathrm{dL}^{4}}{24} \sin (\mathrm{B})\right. \\
\cdot \cos (\mathrm{B})^{3} \cdot\left(5-\mathrm{t}^{2}+9 \eta^{2}+4 \eta^{4}\right)+\frac{\mathrm{dL}^{6}}{720}\left(\sin (\mathrm{B}) \cos (\mathrm{B})^{5}\right) \cdot \\
\left.\cdot\left(61-58 \mathrm{t}^{2}+\mathrm{t}^{4}+270 \eta^{2}-330 \eta^{2} \mathrm{t}^{2}\right)\right]
\end{gathered}
$$

where:

B, L $\quad-$ measured ellipsoidal DGPS coordinates (ref. WGS-84)

$\mathrm{R} \quad-$ radius of curvature in the prime vertical

$\mathrm{S}(\mathrm{B}) \quad-$ distance from the equator to defined coordinate B

$\mathrm{dL} \quad-$ difference in longitude between $\mathrm{L}$ and prime meridian

$\mathrm{k}=0.999923-$ scale factor.

Others parameters could be calculated as:

$$
\begin{gathered}
t=\operatorname{tg}(B) \\
\eta=\frac{e^{2} \cos (B)^{2}}{1-e^{2}}
\end{gathered}
$$

where:

e - eccentricity of ellipsoid

$\eta-$ orientation angle of distortion ellipsis.

All calculations were realized in Mathcad, software version 13.1. Drawings below present scatter plots of the position solution for DGPS relative to past and current status. These fixes are presented with reference to average position (average latitude and average longitude).

Figure 3 presents a comparison of the time series of position errors measured during these two campaigns.

Cumulative statistics of accuracies are presented in tables no. 2 and 3.

The same analysis was done for the absolute accuracy - but relative to true (surveyed) coordinates of reference point. (Tab. 3).

Final analysis was done regard to vertical position error - see fig. 4.

Table no. 4 presents final statistics of the measurements realized for both campaigns.

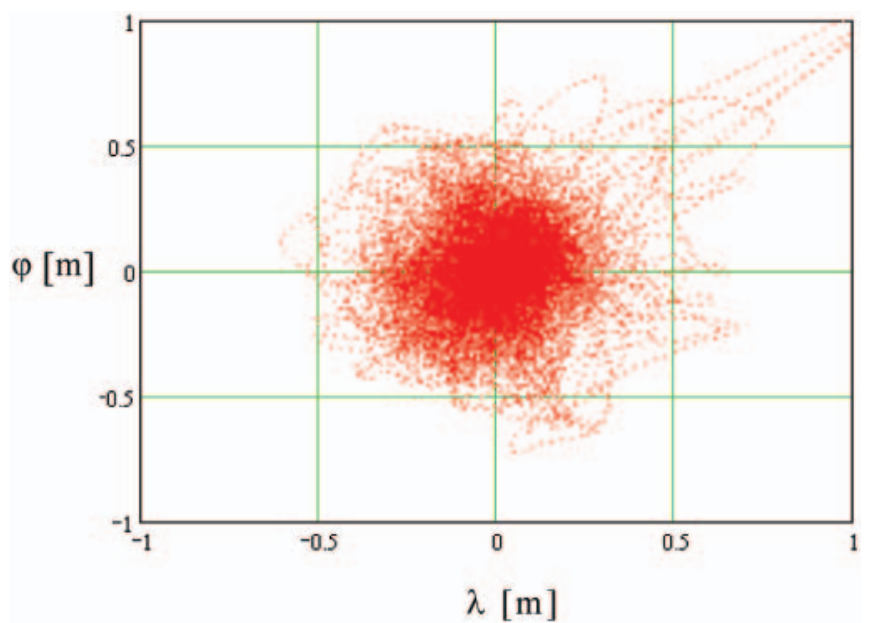

Fig. 2. Scatter plots relative to average position (left - previous, 2005, right-current, 2009) 
Tab. 2. Statistic of position repeatable accuracy - results of the Rozewie DGPS station before May 2005 and after modernization (September 2009)

\begin{tabular}{|c|c|c|c|c|c|c|}
\hline \multirow[b]{2}{*}{$\begin{array}{l}\text { Repeatable } \\
\text { Accuracy }\end{array}$} & \multicolumn{3}{|c|}{ Rozewie DGPS before modernization } & \multicolumn{3}{|c|}{ Rozewie DGPS after modernization } \\
\hline & $\underset{[\mathrm{m}]}{\operatorname{rms}(p=0.68)}$ & $\begin{array}{c}2 \mathrm{rms}(\mathrm{p}=0.95) \\
{[\mathrm{m}]}\end{array}$ & $\begin{array}{c}95 \% \\
\text { population } \\
{[\mathrm{m}]^{*}}\end{array}$ & $\begin{array}{c}\text { rms } \\
(p=0.68) \\
{[\mathrm{m}]}\end{array}$ & $\begin{array}{c}2 \mathrm{rms} \\
(\mathrm{p}=0.95) \\
{[\mathrm{m}]}\end{array}$ & $\begin{array}{c}95 \% \\
\text { population } \\
{[\mathrm{m}]^{*}}\end{array}$ \\
\hline $\begin{array}{l}\text { 3D position } \\
\text { error }\end{array}$ & 1.757 & 3.515 & 3.055 & 0.402 & 0.804 & 0.737 \\
\hline $\begin{array}{l}\text { 2D position } \\
\text { error }\end{array}$ & 1.0202 & 2.040 & 1.769 & 0,210 & 0.420 & 0.385 \\
\hline $\begin{array}{l}\text { 1D- Longitude } \\
\text { error }\end{array}$ & 0.6204 & 1.240 & 1.244 & 0.127 & 0.254 & 0.247 \\
\hline $\begin{array}{l}\text { 1D- latitude } \\
\text { error }\end{array}$ & 0.809 & 1.619 & 1.540 & 0.167 & 0.334 & 0.341 \\
\hline
\end{tabular}

Columns rms and 2rms in table 2 assume Gaussian error distribution, while column "95\% population"

represents measured error value calculated by sorting a population of error values from minimum to maximum.

Tab. 3. Statistic of position absolute accuracy - results of the Rozewie DGPS station before (May 2005) and after modernization (September 2009)

\begin{tabular}{|c|c|c|c|c|c|c|}
\hline \multirow[b]{2}{*}{$\begin{array}{l}\text { Absolute } \\
\text { Accuracy }\end{array}$} & \multicolumn{3}{|c|}{ Rozewie DGPS before modernization } & \multicolumn{3}{|c|}{ Rozewie DGPS after modernization } \\
\hline & $\begin{array}{c}\operatorname{rms}(p=0.68) \\
{[\mathrm{m}]}\end{array}$ & $\begin{array}{c}2 \operatorname{drms}(p= \\
0.95) \\
{[\mathrm{m}]}\end{array}$ & $\begin{array}{c}95 \% \\
\text { population } \\
{[\mathrm{m}]^{*}}\end{array}$ & $\begin{array}{c}\operatorname{rms}(p=0.68) \\
{[\mathrm{m}]}\end{array}$ & $\begin{array}{c}2 \mathrm{rms} \\
(\mathrm{p}=0.95) \\
{[\mathrm{m}]}\end{array}$ & $\begin{array}{c}95 \% \\
\text { population } \\
{[\mathrm{m}]^{*}}\end{array}$ \\
\hline $\begin{array}{l}\text { 3D position } \\
\text { error }\end{array}$ & 1.757 & 3.515 & 3.039 & 0.402 & 0.804 & 1.204 \\
\hline $\begin{array}{l}\text { 2D position } \\
\text { error }\end{array}$ & 1.020 & 2.040 & 1.787 & 0.210 & 0.420 & 0.398 \\
\hline $\begin{array}{c}\text { 1D- Longitude } \\
\text { error }\end{array}$ & 0.620 & 1.240 & 1.245 & 0.167 & 0.334 & 0.344 \\
\hline $\begin{array}{l}\text { 1D- latitude } \\
\text { error }\end{array}$ & 0.809 & 1.619 & 1.549 & 0.127 & 0.254 & 0.270 \\
\hline
\end{tabular}

Columns rms and 2rms in table 2 assume Gaussian error distribution, while column "95\% population"

represents measured error value calculated by sorting a population of error values from minimum to maximum.

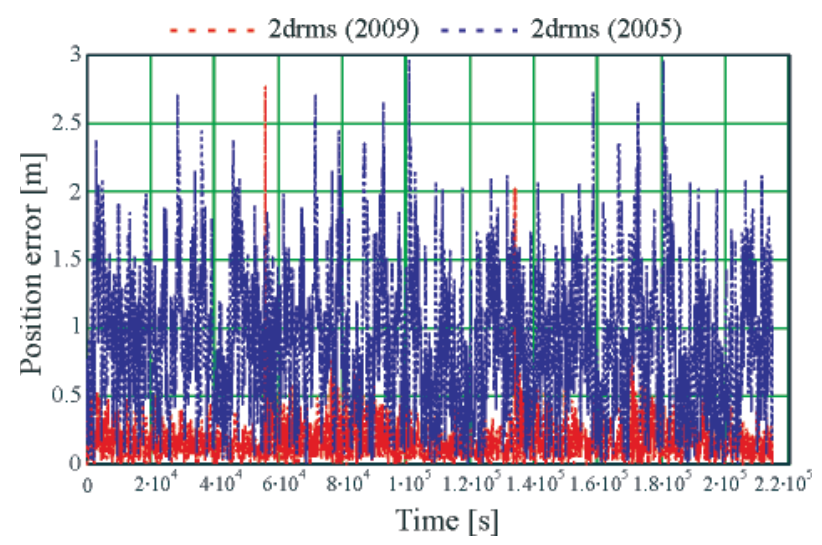

Fig. 3. DGPS position error (2D) as a function of time

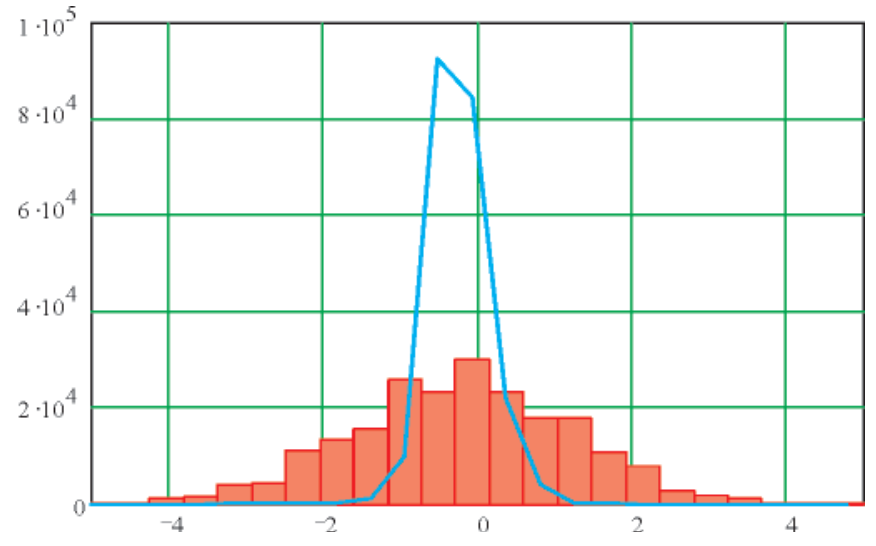

Fig. 4. Histograms of the DGPS vertical position errors measured in 2005 (red) and 2009 (blue) calculated for 2.15.000 position fixes

Tab. 4. Statistics of vertical accuracy results

\begin{tabular}{|c|c|c|c|c|c|c|}
\hline & \multicolumn{3}{|c|}{ DGPS before (May 2005) } & \multicolumn{3}{c|}{ DGPS after (September 2009) } \\
\hline $\begin{array}{c}\text { Type of the } \\
\text { accuracy }\end{array}$ & $\begin{array}{c}\mathrm{rms}(\mathrm{p}=0.68) \\
{[\mathrm{m}]}\end{array}$ & $\begin{array}{c}2 \mathrm{rms}(\mathrm{p}=0.95) \\
{[\mathrm{m}]}\end{array}$ & $\begin{array}{c}95 \% \text { of population } \\
{[\mathrm{m}]}\end{array}$ & $\begin{array}{c}\mathrm{rms}(\mathrm{p}=0.68) \\
{[\mathrm{m}]}\end{array}$ & $\begin{array}{c}2 \mathrm{rms}(\mathrm{p}=0.95) \\
{[\mathrm{m}]}\end{array}$ & $\begin{array}{c}95 \% \text { of population } \\
{[\mathrm{m}]}\end{array}$ \\
\hline Repeatable & 1.431 & 2.862 & 2.834 & 0.343 & 0.686 & 0.674 \\
\hline Absolute & 1.433 & 2.866 & 2.800 & 0.341 & 0.682 & 1.200 \\
\hline
\end{tabular}


Absolute error of DGPS corrected position estimated by long term static observations allows to calculate error vector between estimated (average) and surveyed position. For 2005 year campaign the differences in $3 \mathrm{D}$ cartesian frame were as: $\mathrm{dX}=0.0445 \mathrm{~m}, \mathrm{dY}=-0.162 \mathrm{~m}$ and $\mathrm{dZ}=0.034 \mathrm{~m}$. The same values for present (2009) status are: $\mathrm{dX}=0.013 \mathrm{~m}, \mathrm{dY}=-0.046$ $\mathrm{m}, \mathrm{dZ}=0.574 \mathrm{~m}$.

\section{CONCLUSIONS}

- Evaluation of the DGPS system was performed to gain a statistical comparison of signal quality before 2005 and current operation. Static test of repeatable and absolute position accuracy was done for the Rozewie reference station.

- It should be noted that $95 \%$ current $2 \mathrm{D}$ positions calculated was closer to the reference point then $0.42 \mathrm{~m}$.

- Repeatable and absolute accuracies are nearly the same.

- In comparison to former system operation the position error is about 5 times less.

- An absolute error of 2D position was estimated to be $0.047 \mathrm{~m}$.

- Vertical error distribution is shown in fig.4. In comparison to former results (2005), it is also more than 4 times closer to the reference point. However, there is a significant error in absolute vertical error component $\mathrm{Z}$ (height): $0.57 \mathrm{~m}$. It is very likely, it happened due to a survey error of the reference point position, which should be checked.

In conclusion, it should be noted that DGPS corrections' quality of the modernized DGPS system was analytically proved to be better then the former one.

\section{BIBLIOGRAPHY}

1. Dziewicki M.: Modernization Of Maritime DGPS in Poland, TransNav'2009 Conference, Maritime Academy in Gdynia, 2009

2. IALA, Recommendation R-121: Recommendation on the Performance and Monitoring of DGNSS Services in the Frequency Band 283.5 - $325 \mathrm{kHz}$, June 2004

3. IALA, Recommendation R-135: On The Future of DGNSS, Edition 1, December 2006

4. Specht C.: DGPS and EGNOS Systems in Hydrographic Survey - Accuracy Analyses at the Polish Sea Area, Annual Journal of Hydroacoustics, Committee on Acoustics of the Polish Academy of Sciences, Volume 10, May 2007

5. SPS, Global Positioning System Standard Positioning Service, Performance Standard, Assistant Secretary of Defense, October 2001.

\section{CONTACT WITH AUTHORS}

Marek Dziewicki, M. Sc.

Maritime Office Gdynia, Chrzanowskiego 10

81-338 Gdynia, POLAND

e-mail: marekdz@umgdy.gov.pl

Cezary Specht, Assoc. Prof.

Polish Naval Academy, Smidowicza 69

81-103 Gdynia, POLAND

e-mail: c.specht@geodezja.pl 